\title{
Perbandingan porselen kedokteran gigi swa-sintesis berbahan baku pasir felspar Pangaribuan dan Sukabumi
}

\author{
Joseph Gunawan*, Dede Taufik ${ }^{* *}$, Veni Takarini ${ }^{* * *}$, Zulia Hasratiningsih $^{* * *}$ \\ *Pendidikan Dokter Gigi, Fakultas Kedokteran Gigi, Universitas Padjajaran, Bandung, Jawa Barat, Indonesia \\ ${ }^{* *}$ Balai Besar Keramik, Bandung, Jawa Barat, Indonesia \\ ${ }^{* * *}$ Departemen IImu dan Teknologi Material Kedokteran Gigi, Fakultas Kedokteran Gigi, Universitas Padjajaran, Bandung, Jawa \\ Barat, Indonesia \\ *JI Sekeloa Selatan No. 1, Bandung, Jawa Barat, Indonesia; e-mail: joseph.dentamedia@gmail.com
}

Submisi: 20 April 2017; Penerimaan: 2 Mei 2017; Publikasi online: 29 Desember 2017

\begin{abstract}
ABSTRAK
Bahan porselen kedokteran gigi sebagai salah satu restorasi indirek estetik di Indonesia kebanyakan didatangkan dari luar negeri. Indonesia sebenarnya sangat kaya dengan bahan baku porselen kedokteran gigi seperti felspar, silika, dan kaolin. Tujuan penelitian ini adalah melakukan sintesis porselen kedokteran gigi dari 2 jenis pasir alam Indonesia yaitu Pangaribuan dan Sukabumi. Komposisi yang digunakan yaitu $65 \%$ wt felspar, 25\% wt silika, 5\% wt kaolin, dan 5\% wt garam kalium, dicampur kemudian dilakukan fritting serta sintering. Dua komposisi porselen dibuat dengan bahan dasar berbeda yaitu felspar dari Pangaribuan dan Sukabumi. Kedua porselen yang telah disintering kemudian dievaluasi menggunakan X-Ray Diffraction (XRD). Hasilnya adalah kuarsa dan leusit ditemukan pada porselen dengan komposisi pasir Pangaribuan yang juga memberikan hasil lebih translusen secara visual dibandingkan dengan porselen dengan komposisi pasir Sukabumi yang hanya memperlihatkan hasil kuarsa. Hal ini menunjukkan bahwa porselen dengan komposisi bahan dasar pasir Pangaribuan berhasil disintesis dibandingkan komposisi bahan dasar pasir Sukabumi. Penemuan ini dapat memberikan peluang yang baik dalam pembuatan porselen kedokteran gigi yang berasal dari pasir alam Indonesia.
\end{abstract}

Kata kunci: felspar; Pangaribuan; porselen kedokteran gigi; Sukabumi; swa-sintesis

\begin{abstract}
Comparison self-synthesized dental porcelain between feldspar from Pangaribuan and Sukabumi. Dental porcelain material as one of the esthetic indirect restorations in Indonesia is mostly imported. In fact, Indonesia is really rich of natural raw materials, including feldspar, silica, and kaolinite. The aim of this study is to synthesize the dental porcelain made from Indonesia's two different originates, which are Pangaribuan and Sukabumi. This study was prepared by fritting and sintering the mixture of 65\% wt feldspar (from Sukabumi and Pangaribuan), 25\% wt silica, 5\% wt kaolinite, and $5 \%$ wt potassium salt. The porcelains obtained were evaluated using X-Ray Diffraction (XRD). The results revealed that quartz and leucite were found in the composition of Pangaribuan sand that successfully showed more translucencies compared to Sukabumi sand which only imparted quartz on its component. This study shows that dental porcelain from Pangaribuan sand is successfully self-synthesized, on the other hand Sukabumi sand has not been successfully synthesized. These findings develop on a good prospect of esthetic dental porcelain made from Indonesian natural sand.
\end{abstract}

Keywords: feldspar; Pangaribuan; dental porcelain; Sukabumi; self-synthesized

\section{PENDAHULUAN}

Porselen adalah satu dari empat klasfikasi bahan yang digunakan untuk rekonstruksi gigi berlubang, rusak, atau hilang. ${ }^{1}$ Tiga klasifikasi lainnya adalah logam, polimer, dan komposit. Porselen merupakan salah satu bagian dari keramik. ${ }^{2}$ Secara kimiawi, keramik mengandung senyawa dari unsur logam dan unsur non-logam, sedangkan porselen mengandung fase matriks glass dan satu atau lebih fase kristalin. ${ }^{3}$
Porselen merupakan salah satu pilihan restorasi indirek kedokteran gigi yang memiliki tingkat estetik tinggi. Restorasi porselen semakin banyak dipilih karena memiliki biokompatibilitas yang baik dan ketahanan restorasi dalam waktu yang relatif lama., ${ }^{1,2}$ Porselen kedokteran gigi juga dapat dikatakan sebagai restorasi yang superior karena memiliki harga yang cukup mahal, sehingga banyak orang masih menjadikannya pilihan kedua dalam pemilihan bahan restorasi. ${ }^{4}$ Salah satu 
penyebab harga restorasi porselen mahal adalah bahan baku porselen kedokteran gigi di Indonesia masih berasal dari luar negeri, sedangkan potensi endapan bahan baku keramik di Indonesia sangat banyak. ${ }^{5}$

Porselen kedokteran gigi konvensional memiliki bahan dasar silika, felspar, kaolin dengan tambahan pigmen, opacifier, dan glass modifier. ${ }^{1}$ Felspar yang merupakan bahan utama dalam pembuatan porselen begitu pula dengan bahan pendukung seperti kaolin dan silika merupakan pasir alam yang tersebar di Indonesia. Felspar dengan pengotor paling sedikit ditemukan di Aceh dan Sumatera Utara, sedangkan endapan felspar paling banyak ditemukan di Sukabumi. Silika terbaik ditemukan dari daerah Belitung, dan kaolin tersebar dengan kualitas yang hampir sama di seluruh Indonesia. . $, 6,7^{-}$

Bahan baku porselen kedokteran gigi yang dilebur harus menghasilkan komposisi triaksial kalium aluminosilikat yang mengandung kristalin leusit. Kristalin leusit ini merupakan pembeda antara keramik konvensional umum dengan porselen kedokteran gigi, sehingga kristalin leusit menjadi salah satu indikator keberhasilan sintesis porselen kedokteran gigi. Kristalin leusit dapat dideteksi menggunakan uji $X$-Ray Diffraction (XRD), sehingga uji XRD diperlukan untuk membuktikan keberhasilan sintesis..$^{1,3,8}$

Penelitian ini bertujuan untuk membuat porselen swa-sintesis berbahan dasar pasir alam Indonesia, yang diharapkan di kemudian hari dapat menghasilkan salah satu bahan kedokteran gigi yang berasal dari Indonesia. Perbandingan dilakukan untuk mengetahui hasil sintesis antara bahan dasar felspar dengan pengotor paling sedikit dan felspar dengan endapan yang paling banyak di Indonesia.

\section{METODE PENELITIAN}

Penelitian ini dilakukan dengan 3 tahap, antara lain sintesis bubuk porselen dengan cara pencampuran dan fritting, pembuatan porselen dengan proses sintering sehingga menghasilkan massa padat porselen, dan pengujian hasil porselen menggunakan (XRD). Penelitian telah dilakuan pada bulan September-Oktober 2016 bertempat di Balai Besar Keramik, Bandung dan Laboratorium Pengujian tekMira, Bandung.

\section{Sintesis bubuk porselen}

Bubuk porselen pada penelitian ini dibuat dengan 2 jenis bahan baku yang berbeda. Komposisi dasarnya sama yakni $65 \%$ wt felspar, $25 \%$ wt silika, $5 \%$ wt kaolin, dan $5 \%$ wt garam kalium. ${ }^{9,10}$ Perbedaan komposisi berada pada jenis felspar yang digunakan, komposisi pertama (I) menggunakan felspar Pangaribuan, sedangkan komposisi kedua (II) menggunakan felspar Sukabumi. Silika yang digunakan diperoleh dari daerah Belitung dan kaolin dari daerah Sukabumi. Garam kalium didapatkan dari toko bahan kimia.

Pembuatan bubuk porselen diawali dengan pencampuran seluruh bahan dasar sesuai dengan komposisi I dan II melalui proses wet ball-mill dengan media etanol $97 \%$ selama 4 jam. Hasil milling dikeringkan menggunakan oven pengering pada suhu $50{ }^{\circ} \mathrm{C}$ selama 24 jam. Hasil campuran yang sudah kering kemudian dimasukkan ke dalam krusibel berbahan dasar alumina dan dilakukan fritting. Fritting adalah proses pembakaran bahan baku bubuk porselen sampai melebihi titik lebur bahan untuk menghasilkan bubuk keramik yang homogen. Fritting dilakukan pada oven bersuhu $30{ }^{\circ} \mathrm{C}$ yang dinaikkan $200{ }^{\circ} \mathrm{C} / \mathrm{jam}$ selama 6 jam sampai pada suhu $1230{ }^{\circ} \mathrm{C}$, kemudian ditahan selama 5 jam dan diturunkan $125^{\circ} \mathrm{C} / \mathrm{jam}$ selama 2 jam. Penahanan akhir di suhu $1000^{\circ} \mathrm{C}$ dilakukan selama 4 jam.9,10,11 Krusibel langsung dikeluarkan dari oven dan dimasukkan ke dalam air es sampai suhu air sama dengan suhu krusibel. Hasil fritting kemudian dipecahkan dan dipisahkan dari krusibel serta digiling kembali dengan ball-mill sampai berukuran 200 mesh. ${ }^{10,12}$

\section{Pembuatan porselen}

Bubuk porselen yang telah berhasil disintesis, dimanipulasi dengan penambahan sedikit aquades untuk mempermudah pembentukan bahan, Bubuk porselen yang telah dibentuk kemudian dilakukan sintering. Sintering adalah proses pemanasan bubuk sebelum sampai ke titik leburnya untuk 
membentuk massa padat porselen. Bahan yang telah dibentuk dimasukkan ke dalam oven dengan suhu awal $30{ }^{\circ} \mathrm{C}$ dan menaikkannya $50{ }^{\circ} \mathrm{C} / \mathrm{jam}$ sampai mencapai suhu $1100^{\circ} \mathrm{C}$ dan ditahan selama 4 jam. Suhu kembali diturunkan dengan penurunan suhu $50{ }^{\circ} \mathrm{C} / \mathrm{jam}$ sampai mencapai suhu awal dan sampel dikeluarkan dari oven. 3,13,14 $^{2}$

\section{Pengujian XRD}

Porselen yang sudah melalui pembakaran akhir, dilakukan preparasi dengan penggilingan bahan sampai berukuran 200 mesh dan kemudian diuji $X R D$. Pengujian XRD dilakukan di laboratorium pengujian tekMira dengan spesifikasi alat Philips Analytical X-Ray BV Lelyweg 1 tipe 943001830401.

\section{HASIL PENELITIAN}

Porselen dengan komposisi pertama yaitu porselen dengan bahan dasar utama felspar Pangaribuan secara visual memperlihatkan porselen dengan warna putih dan memiliki translusensi yang cukup baik (Gambar 1A), sedangkan porselen dengan komposisi kedua yaitu porselen dengan bahan dasar utama felspar Sukabumi memperlihatkan porselen dengan warna agak kecoklatan serta memiliki translusensi tidak sebaik porselen komposisi pertama (Gambar 1B). Kedua jenis porselen dilakukan uji XRD dan ditemukan dari analisis grafik XRD komposisi pertama (Grafik 1) bahwa porselen tersebut terdapat kalium alumino silikat $\left(\mathrm{KAISi}_{2} \mathrm{O}_{6}\right)$ dengan nama lain kristalin leusit dan juga silikon oksida/kuarsa. Sedangkan pada analisis grafik XRD komposisi kedua (Grafik 2) hanya ditemukan silikon oksida/kuarsa.

Analisis XRD dilakukan dengan melihat 3 puncak tertinggi grafik dengan memperhatikan $2 \theta$ yang memiliki intensitas tertinggi. Analisis XRD komposisi pertama menyatakan $2 \theta$ dengan intensitas tertinggi ada pada 27,13; 25,97; dan 26,59, sedangkan pada komposisi kedua, $2 \theta$ dengan intensitas tertinggi ada pada 26,60; 21,82; dan 20,83 .

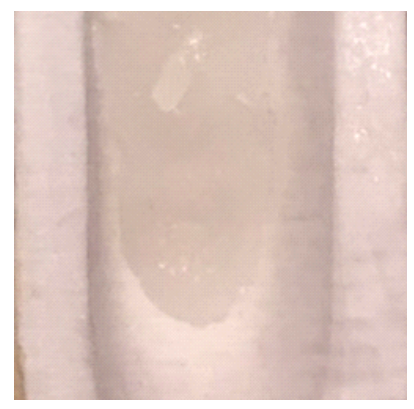

(A)

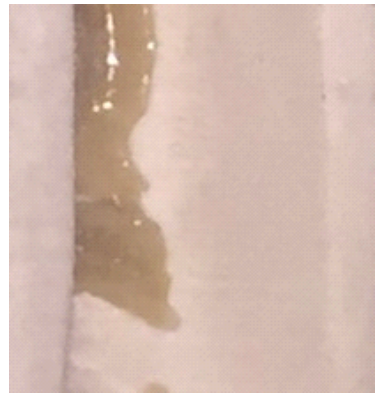

(B)
Gambar 1. Porselen dengan komposisi bahan dasar felspar Pangaribuan (A) dan Porselen dengan komposisi bahan dasar felspar Sukabumi (B)

\section{PEMBAHASAN}

ICDD 15-0047 menyatakan bahwa puncak tertinggi kristalin leusit berada pada 20: 27,34; 25,93; dan 16,52. Hal ini sesuai dengan 2 puncak tertinggi hasil XRD porselen komposisi pertama (Grafik 1). Sedangkan pada porselen komposisi kedua, puncak tertinggi hasil XRD tidak menunjukkan adanya kesamaan dengan ICDD 150047. Hal ini membuktikan bahwa kristalin leusit terdapat pada porselen komposisi pertama yang menandakan bahwa porselen tersebut berhasil menjadi porselen sesuai dengan kebutuhan di bidang kedokteran gigi.

Kristalin leusit penting terbentuk pada porselen kedokteran gigi karena merupakan fase matriks yang dapat meningkatkan kekuatannya dan memperkecil crack propagation karena dapat menyerap energi fraktur. Kristalin leusit juga berfungsi untuk memberikan resistensi terhadap aliran piroplastik berlebih pada proses peleburan sehingga memberikan stabilitas karakteristik pada objek. . $^{1,8}$

Kristalin leusit yang diharapkan terbentuk pada kedua jenis porselen dengan penambahan $5 \%$ garam kalium belum berhasil dilakukan pada porselen komposisi kedua dengan bahan dasar utama felspar dari Sukabumi. Hal ini disebabkan pasir felspar Sukabumi secara alami memang 
hanya memiliki kandungan oksida kalium sebanyak 4,43\% sedangkan pasir felspar Pangaribuan $10,01 \% .{ }^{9}$ Hal tersebut menghasilkan pembentukan kristalin leusit pada porselen komposisi pertama dapat terjadi dengan lebih mudah. Kristalin leusit yang berfungsi sebagai indikator pembeda porselen kedokteran gigi dengan keramik umum menjadi sangat penting ditemukan dalam uji XRD dalam menentukan keberhasilan sintesis porselen kedokteran gigi. ${ }^{8,11}$ Presentase kristalin leusit pada porselen pertama diuji menggunakan X-Ray Fluoroscence (XRF) yang juga memperkuat hasil penelitian dengan hasil 10\%.13,15 XRF merupakan teknik analitik dengan emisi sinar $X$ sekunder yang ditembak oleh sinar $X$ atau gamma tinggi energi dan memberikan hasil berupa presentase komponen pada benda yang ditembak. ${ }^{16,17}$
Selain dari komposisi, kristalin leusit mungkin gagal terbentuk pada porselen komposisi kedua karena ketidaktepatan suhu pembakaran. ${ }^{12,18}$ Porselen yang kurang matang dapat menyebabkan kristalin leusit belum terbentuk sepenuhnya, atau juga porselen yang overheating akan menghasilkan kristalin leusit yang kembali melebur sehingga tidak didapatkan kristalin leusit pada hasil sintering. 1,10,11

Perbedaan visualisasi pada kedua jenis porselen dapat disebabkan perbedaan bahan dasar felspar yang digunakan. Felspar Pangaribuan memiliki pengotor berupa $\mathrm{Fe}_{2} \mathrm{O}_{3}$ sebanyak $0,24 \%$ sedangkan pada felspar Sukabumi pengotor $\mathrm{Fe}_{2} \mathrm{O}_{3}$ terdapat sebanyak $0,94 \% .{ }^{9,11}$ Pengotor oksida besi dapat menghasilkan warna coklat kehitaman, walaupun demikian bahan oksida besi tidak dapat dihilangkan dari komposisi porselen karena

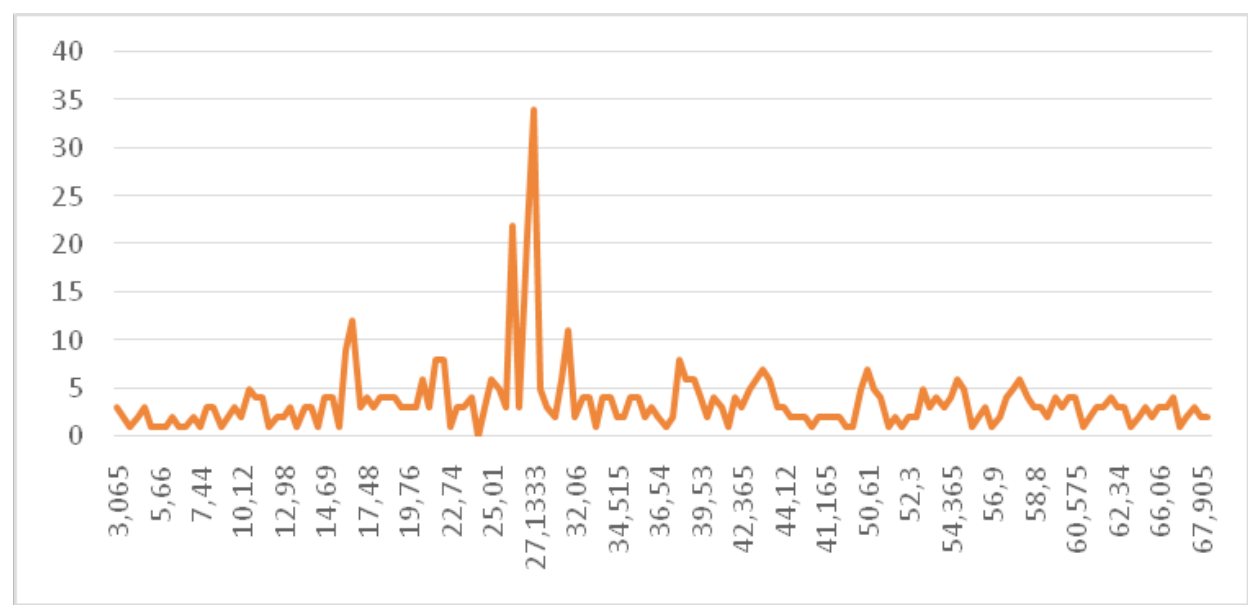

Grafik 1. Hasil uji XRD porselen komposisi pertama

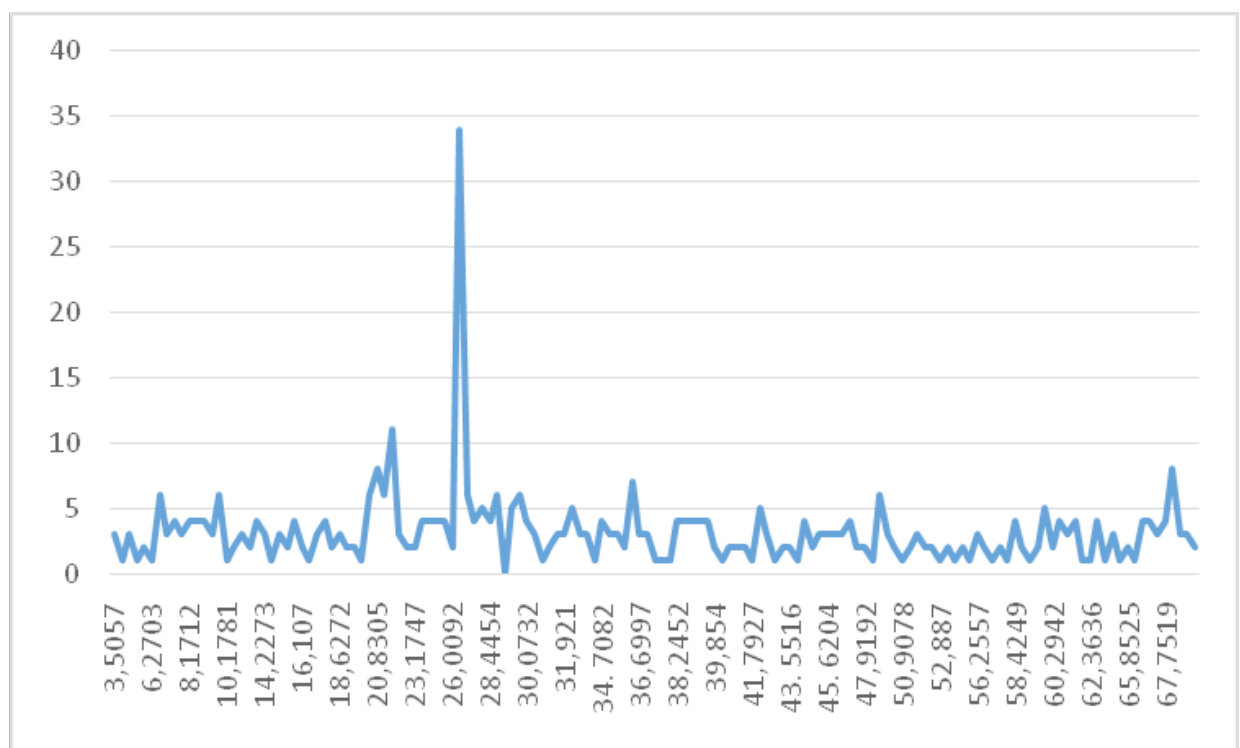

Grafik 2. Hasil uji XRD porselen komposisi kedua 
diperlukan untuk memberikan pigmentasi pada shading porselen kedokteran gigi. ${ }^{1,3} \mathrm{Di}$ sisi lain, translusensi bahan dapat dipengaruhi oleh berbagai hal antara lain ukuran partikel dan kematangan porselen. Ukuran partikel yang semakin kecil dapat menghasilkan ikatan antar partikel yang semakin dekat sehingga dapat menghalangi jalan cahaya, sedangkan kematangan porselen yang kurang sempurna dan pembakaran yang berulang-ulang dapat mengurangi translusensi. ${ }^{2,10}$ Pembakaran tanpa menggunakan tungku hampa udara seperti pada penelitian ini juga mengurangi translusensi karena memungkinkan adanya udara terjebak pada proses pembakaran yang menghalangi jalannya sinar. ${ }^{2,4}$ Hal lain yang mungkin menjadi pembeda translusensi porselen komposisi pertama dan kedua adalah kadar komponen $\mathrm{TiO}_{2}$ yang berbeda pada felspar Pangaribuan $(0,11 \%)$ dan felpar Sukabumi $(0,66 \%) \cdot{ }^{9} \mathrm{TiO}_{2}$ pada porselen kedokteran gigi dapat berfungsi sebagai pigmen dan opacifier.1,4,11

Pembakaran porselen pada penelitian ini mencapai suhu $1100{ }^{\circ} \mathrm{C}$ sebenarnya sudah melebihi suhu pembakaran porselen konvensional yang dipakai pada laboratorium kedokteran gigi yang hanya berkisar pada suhu $900-960{ }^{\circ} \mathrm{C}$ dengan

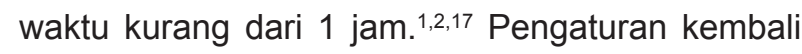
komposisi dapat dilakukan untuk menghasilkan suhu dan waktu pembakaran sesuai dengan manipulasi sehari-hari. Pengujian kekuatan, kekerasan, translusensi, dan biokompatibilitias kemudian dapat dilakukan untuk mendapatkan porselen kedokteran gigi yang sesuai dengan standar.

\section{KESIMPULAN}

Porselen kedokteran gigi dengan komposisi bahan dasar felspar Pangaribuan berhasil disintesis, sedangkan dengan komposisi bahan dasar felspar Sukabumi belum berhasil disintesis.

\section{UCAPAN TERIMA KASIH}

Penelitian ini dapat terlaksana atas kesempatan kerja sama dengan laboratorium riset keramik konvensional milik Balai Besar Keramik dan Pusat Penelitian dan PengembanganTeknologi Mineral dan Batubara dalam pelaksanaan uji XRD. Kami ucapkan terimakasih pula atas dana hibah Riset Fundamental Universitas Padjajaran.

\section{DAFTAR PUSTAKA}

1. Babu PJ, Alla RK, Alluri VR, Datla SR, Konakanchi A. Dental ceramics: Part I An overview of composition, structure, and properties. Am JMaterials Eng and Tech. 2015; 3(1): 13 - 18.

2. Anusavice K. Phillips' Science of Dental Material. 12th ed. Amsterdam: Elsevier; 2013. $680-740$.

3. Ivoclar Vivadent. Scientific Documentation IPS Classic. Research \& Development Scientific Service: Liechtenstein; 2011.

4. Raghavan RN. Ceramics in Dentistry, Sintering of Ceramics - New Emerging Techniques, Dr. Arunachalam Lakshmanan (Ed.), ISBN: 978953-51-0017-1, Croatia: InTech; 2012 [cited 2016 October 20] Available from: http://www. intechopen.com/books/sintering-of-ceramicsnew-emerging-techniques/ceramics-indentistry.

5. Direktorat Jenderal Agro Industri \& Departemen Perindustrian. Roadmap industri keramik. Jurnal Dirjen Agroindustri. 2009; 21: $1-10$.

6. Adrian. Potensi batuan pegmatif Pangaribuan sebagai sumber alumina dan alkali untuk pembuatan gelas dan kaca. Makalah Direktorat Jenderal Geologi dan Sumber Daya Mineral. 2001; 3: 1 - 20.

7. Simanjuntak S. Inventarisasi dan evaluasi mineral logam di daerah kabupaten Cianjur dan kabupaten Sukabumi, provinsi Jawa Barat. Jurnal Kementerian Energi dan Sumber Daya Mineral. 2002; 2: 1 - 20.

8. Helvey GA. Classification of dental ceramics. Inside Continuing Education. 2013; 13: 62 - 68.

9. Katz S. Translucent dental porcelain composition, its preparation and a restoration made thereof. European Patent Application. 1987; 53(9): $1-15$. 
10. Panzera C, Mead B, Kalser LM. Dental Porcelain Composition. United States Patent Application. 1999; 54(17): $1-6$.

11. Kelly JR, Benetti P. Ceramic materials in dentistry: historical evolution and current practice. Australian Dental Journal. 2011; 56(1): $84-96$.

12. Iyasara AC, Joseph M, Azubuike TC. The use of local ceramic materials for the production of dental porcelain. American Journal of Engineering Research. 2014; 3(9): 135 - 139.

13. Carter CB, Norton MG. Ceramic Materials Science and Engineering. 1st ed. New York: Springer Science; 2007. 365 - 380.

14. Denry I, Holloway JA. Ceramics for dental applications: A review. J Mater 2010; 3(1): $351-368$.
15. Boch P, Niepce J. Ceramic Materials Processes, Properties, and Applications. 2nd ed. Wiltshire: Antony Rowe Ltd.; 2007. $130-155$.

16. Rohayati Y. Sertifikat analisis XRF. Laboratorium Pengujian tekMira: Bandung. 2016. No: 1635/LFM/XI/2016-6423-6425

17. Wang F, Takahashi H, Iwasaki N. Translucency of dental ceramics with different thicknesses. J Prosthet Dent. 2013; 110(1): 14 - 20.

18. Nurddin SMAS, Selamat M. Development of leucite glass-ceramics for non-metallic dental product. J. Chemical Eng. and Materials Sci. 2015; 7(2): 11 - 17. 